\title{
Indigenous place names in toponymical strata on the Turtle Island
}

\author{
Ferland, Yaïves* \\ Université Laval, Québec, Canada, yaives.ferland@scg.ulaval.ca \\ * Corresponding author
}

Keywords: Indigenous place names, toponymical strata, North America

\begin{abstract}
:
The problematic question of the degree of real correspondence between place names and the geographical features or entities has formal interest only about the capability of the name to represent the multiple levels of meaning in the structuration process of a place for the concerned people. As long one considers essentially the label of a toponym applied specifically to that place, even from a linguistic or historical perspective to decipher its roots, the results remain generally anecdotal, although one may compose a corpus of justified examples for more serious studies. Be they descriptive, possessive, narrative, allusive, evocative or commemorative (in terms of anthroponyms or hagionyms), most placenames stands as metonyms, metaphors, or connotations without clear link to the place neither to the spatial relationships among the area.

Our deep and longstanding interest on territorial organisation of toponymical strata that spread across North America (called the 'Turtle Island' in some Algonquian languages about their myth of creation of the land) over five centuries provided a methodological framework for comprehension of the place naming practices. These ones have evolved through purposes, policies, eras, and areas (note that it does not constitute a formal toponymical theory for ideal explanation). The development of naming forces were not the same in periods of: aboriginal occupation, colonial settlement, imperial conquest, political nation-building, ethnical immigration, cultural appropriation, technological innovation, administrative normalization and usage, overwhelming commemoration, cultural vogues, ...

One characteristics appears quite dominant (but not constant) in naming, adopting, translating, deforming, or replacing place identifiers from one language to another: if original in pronunciation and spelling forms, that looks exclusive within some administrative levels. Aboriginal names that seemed preserved appear in adaptive spellings depending the language of explorers, merchants and colonists; the French, Spanish, English and a few Dutch. But, even where they were descriptive and convenient for their proper places, in most part they remains opaque to the current language of the respective tribes or nations, mainly because put out of their cultural contexts and manners to refer by names. Among other characteristics, adding "New" or combining two strata of entities (a hagionym with a township name for instance), reveal some aspects of geographical structures in settlement, division, and development of the land possessed by a European power. Such pragmatic arguments may help to manage social tensions in actual debates for naming new places, removing problematic ones, or renaming existing places, institutions, and buildings, since names stand as symbols of place identity.

Over the past decades, Indigenous nations affirm their identity while claiming for reconciliation and decolonization by inventory of place names, among other means. To address positively this challenge, some toponymical authorities adopt protocols and policies in an effort to restore ancient Indigenous toponymies as well as to implement new toponyms that emerge from their rejuvenate languages, into the official cartographies. This restoration links the leadership shown by Indigenous communities with local and international experts and organisations to search functional solutions standardization, meaning, and generics for unconventional 'entities' with fuzzy definitions or limits, like seasonal pathways. Nevertheless, in many parts of North America, we see the dawn of a new toponymical stratum that will correspond to an ancient conception of the land we live on. That deserves a presentation.
\end{abstract}

